\title{
Phenotypic Variability of Leigh Syndrome Due to the ATP6/ATP8 Variant M.8561T $>C$
}

\author{
*Corresponding Author \\ Finsterer J, MD, PhD

\section{Article History} \\ Received: 27.01 .2020 \\ Accepted: 03.02 .2020 \\ Published: 09.02.2020
}

Josef Finsterer, $\mathrm{MD}, \mathrm{PhD}^{*}$

Krankenanstalt Rudolfstiftung, Messerli Institute, Vienna, Austria

Keywords: Heteroplasmy, mtDNA, oxidative phosphorylation, Leigh syndrome, lactic acidosis.

\section{LETTER TO THE EDITOR}

With interest we read the article by Fugaki et al. about a 13yo male with Leigh syndrome(LS) manifesting as microcephaly, developmental delay, ataxia, bradyphrenia, learning difficulty, hypotonia, dysarthria, gait disturbance, retinal hypoplasia, exercise-intolerance, and bilateral basal ganglia lesions, being attributed to the mtDNA variant m.8561T>C in ATP6/ATP8[1]. The study raises concerns.

There is an evident discrepancy between the normal muscle biopsy and the heteroplasmy rate of $96 \%$ in muscle and the complex-V deficiency on biochemistry. We should know if the muscle was clinically affected, meaning if hypotonia was due to myopathy, if tendon reflexes were reduced, if there was muscle weakness/wasting, elevated creatine-kinase, or a myopathic electromyography.

Another discrepancy refers to the heteroplasmy rate of the variant in muscle. In the results the heteroplasmy rate is reported as $96 \%$ but $99 \%$ in the discussion. We should know which figure is correct.

Serum lactate was slightly elevated but lactate levels in the cerebrospinal fluid (CSF), or MR-spectroscopy were not provided. Cerebral lactate is frequently elevated on LS [2].

In $75 \%$ of the mtDNA variants maternal transmission can be documented [3]. Since the mother carried the variant with a heteroplasmy rate of $12 \%$ in urine, buccal mucosa, and blood, she was most likely the carrier. We should know if she was prospectively investigated for mild or subclinical manifestations of a mitochondrial disorder, in particular LS. We should know if the sister of the index patient was clinically or genetically affected.

It should be explained why the phenotype of the index patient and the previously described patient with a similar mutation [4] was at variance. Heteroplasmy rates were the same, thus not explaining the phenotypic variability.

Overall, this interesting case could be more meaningful if the above mentioned discrepancies and shortcomings were sufficiently addressed. Cerebral lactate should be provided and the phenotypic variability between families explained.

\section{REFERENCES}

1. Fragaki, K., Chaussenot, A., Serre, V., Acquaviva, C., Bannwarth, S., Rouzier, C., Chabrol, B., Paquis-Flucklinger, V. (2019). A novel variant $\mathrm{m} .8561 \mathrm{C}>\mathrm{T}$ in the overlapping region of MT-ATP6 and MT-ATP8 in a child with earlyonset severe neurological signs. Mol Genet Metab Rep, 21:100543.

Copyright @ 2020: This is an open-access article distributed under the terms of the Creative Commons Attribution license which permits unrestricted use, distribution, and reproduction in any medium for non commercial use (NonCommercial, or CC-BY-NC) provided the original author and source are credited. 
2. Harbulot, C., Paquay, S., Dorboz, I., Pichard, S., Bourillon, A., Benoist, J.F., Jardel, C., Ogier de Baulny, H., Boespflug-Tanguy, O., Schiff, M. (2016). Transient neonatal renal failure and massive polyuria in MEGDEL syndrome. Mol Genet Metab Rep, 7:8-10.

3. Poulton, J., Finsterer, J., Yu-Wai-Man, P. (2017). Genetic Counselling for Maternally Inherited Mitochondrial Disorders. Mol Diagn Ther, 21:419-429.

4. Kytövuori, L., Lipponen, J., Rusanen, H., Komulainen, T., Martikainen, M.H., Majamaa, K. (2016). A novel mutation $\mathrm{m} .8561 \mathrm{C}>\mathrm{G}$ in MT-ATP6/8 causing a mitochondrial syndrome with ataxia, peripheral neuropathy, diabetes mellitus, and hypergonadotropic hypogonadism. J Neurol, 263:2188-2195. 